\title{
Concept Map in Knowledge Sharing Model
}

\author{
H. Hussain and N. R. Shamsuar
}

\begin{abstract}
Concept maps are widely used in education and business as a first step in knowledge sharing between the groups of people in communicate their complex idea and creativity. However, the mapping process is quite complex because all of the inherent ambiguity in aid creativity and ideation must be resolved to produce the facilitative tool for knowledge sharing model. This study has intended to show how concept map based knowledge models can be used as facilitator tools in create, locate and disseminate information in a way that makes them easily browsable. Therefore, the use of concept map will be explored in ideation of generating the game genre and extendable to the educational platform in organized their knowledge in an experimented method. This study shows that the fundamental of knowledge is rooted then individuals can readily apply it to multiple contexts. Thus the implementation of visualization tool will be studied using the experimental method which will be leading the development of knowledge sharing model.
\end{abstract}

Index Terms - Concept map, knowledge sharing, knowledge lifecycle, knowledge sharing model, facilitative tool.

\section{INTRODUCTION}

Concept maps are a structured hierarchically, with more general, more inclusive concepts higher in the structure. The structure of a concept map is dependent on its context. Consequently, maps having similar concepts can vary from one context to another and are highly idiosyncratic. For game designers, the strength of concept maps lies in their ability to measure a particular person's knowledge about a given topic in a specific context. Thus, concept maps constructed by different persons on the same topic are necessarily different, as each represents its creator's personal knowledge.

Similarly, we cannot refer to the correct concept map about a particular topic, as there can be many different ways to develop logical thinking and study skills by revealing connections and helping students see how individual ideas form a larger whole [1]. When concepts and linking words are carefully chosen, these maps are powerful tools for observing nuances of meaning. Their rich, expressive power derives from each map's ability to allow its creator to use a virtually unlimited set of linking words to show how meanings have been representations of the topic that are correct [2].

Fig. 1 show the basic concept map by Novak \& Govin as opposed to knowledge domain and context [2].

In this study, concept map is used to absorb knowledge, or convince others or even the designers that they understand a topic. It can be precise and verifiable. As we know, nobody can know everything but only to know about a particular domain of knowledge, with the fact that knowledge is always not complete, it is partial within the individuals. The real problems need to be solved by taking advantage of the partial understanding of the context problem data [3].

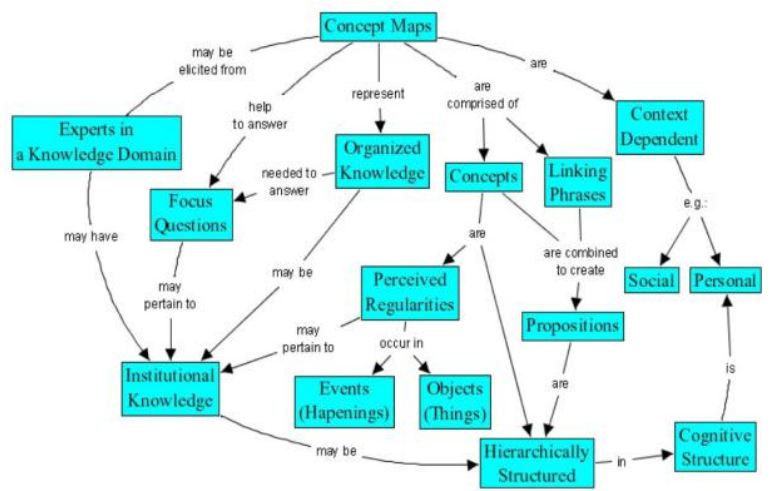

Fig. 1. Concept map about concept maps [2].

Knowledge has changed because of the way of interaction within knowledge, changes has occurred in the context in which knowledge exist and in the flow and characteristic of the knowledge itself. Thus, knowledge management is a theory that seeks to understand in which way knowledge is created, shared and used within organizations.

Knowledge always begins with some type of knowledge creation and then moves through the following four stages:

1) Creation: The ability to create the work of others to make the initial knowledge better.

2) Dissemination: Analysis, evaluation, and filtering elements through the network communication

3) Personalization: Acknowledge the knowledge to ourselves through the experience of internalization, dialogue, or reflection.

4) Implementation: At this stage, the feedback to the personalization stage will be used to create or make an innovation of a concept.

Nowadays, most organizations use knowledge assets to generate profits and add value. Organization share knowledge to help them focus on other more important things, such as innovation and creation and by making knowledge available to be shared, they gained the status of trustworthy and transparency.

In a world of knowledge information and knowledge sharing, this is the key ingredient to success which the facilitating effects of social networks is found to be partially mediated by motivational factors in knowledge transfer [4].

\section{KNOWLEDGE SHARING MODEL}

supported in part by the Multimedia University under MiniFund Cycle $1 / 2011$.

H. Hussain is with the Multimedia University, Cyberjaya 63100 Malaysia (e-mail: hanafizan.hussain@mmu.edu.my,

Natalya.shamsuar@1mmu.edu.my).

\section{A. Knowledge Sharing}

Organizations have sought knowledge management as 
increasing number of theories and practitioners have insisted that organizational knowledge is a major source of competition advantage [5]. Knowledge sharing is significant in that knowledge held by individuals cannot become organizational knowledge until it is shared throughout the organization [6]. Knowledge sharing is an activity of information, skill or expertise which is considered as knowledge is exchanged among people, friends, or members of a family, a community or an organization.

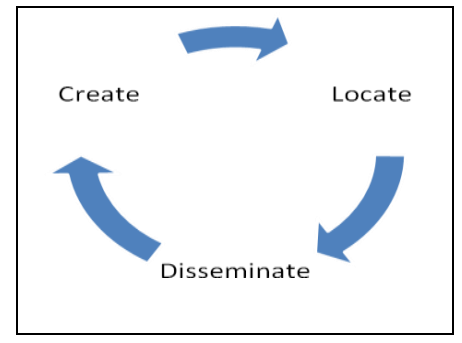

Fig. 2. Knowledge sharing phase.

Fig. 2 shows that the sharing knowledge starts within the individuals to create locate and disseminate idea or information in organization.

Knowledge sharing is essential in the implementation of any knowledge management initiative. The real sharing required is between the individuals (e.g. employees) within the organizations (e.g. their co-workers). The actual success depends on individuals' willingness to encourage and share their organizational knowledge through internal organizational social exchanges using the knowledge sharing phase as shown in Fig. 2.

\section{B. Knowledge Sharing Lifecycle}

The nature of knowledge has been defined by allowing the identification of knowledge as it pertains to the organization itself. For the knowledge sharing lifecycle in the information management, the model by Newman has been more on the explicit knowledge [7].

These are the processes associated with gathering and disseminating existing knowledge. For most knowledge management programmers, this is the primary focus. Knowledge is stored in one or more repositories, such as computer storage for explicit knowledge and people's heads for tacit knowledge.

Fig. 3 shows the knowledge sharing lifecycle which is more relates to explicit knowledge. According to the Data-Information-Knowledge-Technology (DIKT) model [7] on information management there will be more complete variation of this cycle using information management terminology.

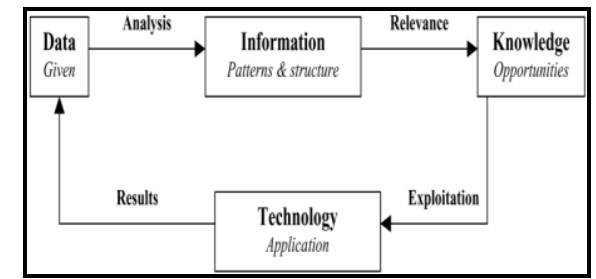

Fig. 3. The DIKT model [7].

Among the Information Life Cycle are below:

- Create/collect. New knowledge is created or existing knowledge is gathered. A knowledge audit is a good technique for discovering what exists.

- Organize/store. The knowledge is classified and stored, perhaps using a company specific taxonomy. This makes subsequent retrieval easier.

- Share/disseminate. Information may be 'pushed' to people as part of routine dissemination or it may be simply 'parked' in information repositories for individuals to access it when needed. For tacit knowledge, this part of the cycle involves knowledge transfer activities such as meetings.

- Access. Individuals browse or search their organization's information and document repositories, typically via an intranet. Users 'pull' the information when they need it.

- Use/exploit. They use this knowledge to carry out specific tasks. As they use it the knowledge is evaluated, refined and improved. As a result new knowledge is created and the cycle repeats.

These activities which monitor the processes (e.g. production processes or customer sales behavior) produce only the data. These are unstructured streams of numbers or characters that only have relevance when viewed within a specific context. This requires analysis to achieve, by converting the data into information, to reveal structures and patterns within it.

If this information can be exploited by the organization, it constitutes knowledge which can contribute to lower costs, improved product and process performance, or the development of new market concepts to the organization. Thus knowledge may be viewed as a higher form of information, elevated by the specific nature and purpose of the organization, to provide an opportunity that the organization can exploit for its advantage.

Finally, the knowledge may be deployed via a technology (e.g. a new method or machine). If this affects the process being monitored, it will form a feedback loop. The most common objective for a knowledge visualization tool is to make visible an intellectual landscape. This landscape can be represented as a knowledge map that can serve as a common framework or context for the purpose of knowledge sharing, decision-making and problem-solving [8].

\section{Knowledge Sharing Models}

Nonaka and Takeuchi have identified two categories of knowledge which are explicit and tacit knowledge [9]. Explicit knowledge is a scientific "rule", which may be justified from first principles. Because its origins and basis are known, this type of knowledge is easily transferable, both within and outside an organization and between people.

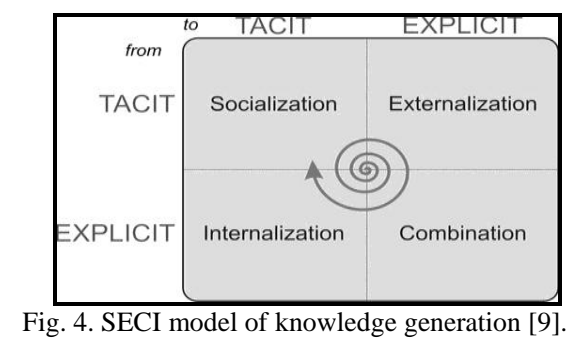

Conversely, as shown in Fig. 4, tacit knowledge is a heuristic "rule of thumb", derived empirically and held by the organization's employees or embedded in long-held practices. Tacit knowledge is thus more difficult to challenge, more 
difficult to transfer, and more easily lost to an organization.

In this study, the knowledge or concept mapping is merely the means to a more important end: that of supporting deep understanding of subject matter knowledge and concepts.

\section{CONCEPT MaP As Facilitative ToOL}

One of the diagrammatic techniques of knowledge used in this study is concept map. Originally, concept map has been used as a facilitative tools to accesses the understanding of any topic within the education community. Using concept map as a facilitative tool, the fundamental of knowledge in designing games can be supported for deeper understanding in the subject matter and design skills.

In a concept map, each word or phrase is connected to another and linked back to the original idea, word or phrase. Therefore, for game designers they have the ideas but the important of the multiple learning and discovery should be rooted then they can readily apply it to other disciplinary contexts in designing games.

Currently, the game designers when they are undertaking the development of games, they always start with the brainstorming session. In the brainstorming session, the ideations of games are based on their principles of learning environments that facilitate the creation of game itself. The expression of their knowledge and understanding for the new creation of the game can be drawn in simple diagrammatic techniques of knowledge.

For this study the diagrammatic technique of knowledge that will be is Concept Mapping. There are a few of software that can be studied such as CmapTool, MindMapping, ThinkMap, TreeMapTool, etc. All these are visualization techniques which can facilitate the ideation and creation of new games for specific disciplinary contents. They provide a graphical user interface to construct concept maps which support for hyperlinks, and collaboration tool.

These knowledge maps help you organize information in such a way that you gain greater insight into the knowledge and therefore be able to take the necessary action steps to turn the information into useful concepts for your organization or for educational purpose.

Purposes of concept mapping are:

- To generate ideas (brainstorming etc.)

- To design a complex structure (long text, hypermedia, large websites or complex projects)

- To communicate complex ideas

- To aid learning by explicitly integrating new and old knowledge

- To assess understanding or diagnose misunderstanding.

Concept Mapping is used as a framework to learn new knowledge; it starts with a focus question. It arranges the concept in patterns that best represents the information. It also uses arrows which can be single or double headed to link terms that are related. Each line should have a label that describes the relationship between the two terms it connects.

Concept map tend to be nouns and linking phrases are usually verbs, and it is recommended that both consist of as few words as possible. Linking phrases can express any type of relationship, and are not limited to a defined set (e.g., is-a, part-of, etc.) as in other diagramming techniques such as semantic networks. However, it is this freedom in the construction of linking phrases in particular that prevents concept maps from being automatically translatable to any formal representation.

In a "well-constructed" concept map,

1) Each pair of concepts, together with their joining linking phrase, can be read as an individual statement or proposition that makes sense. Hoffman and the other researchers referred to a concept map where all the triples (concept, linking phrase, and concept) are well-formed propositions, as being propositional coherent [11]. In addition, in well-constructed concept maps:

2) Concepts and linking phrases are as short as possible, possibly single words.

3) The structure is hierarchical and the root node of the map is a good representative of the topic of the map.

The concept map has been applied in this course to grab the attention of creating idea or enhancing game genre in their perspective of knowledge. Therefore the use of concept map has been studied in creating idea on games genre in organizing their knowledge in game creation. Through the specific theme as a bench marking in creating ideas, the conceptual approach in generating idea for game designer needs to be enhanced by using visualization tools to capture the knowledge on the specific content.

The experimental group has been focused on the software and game design students in their first year of taking their majoring courses. At the beginning the paper-based concept map has been applied towards these students. This has been one of the activities in understanding the games genre.

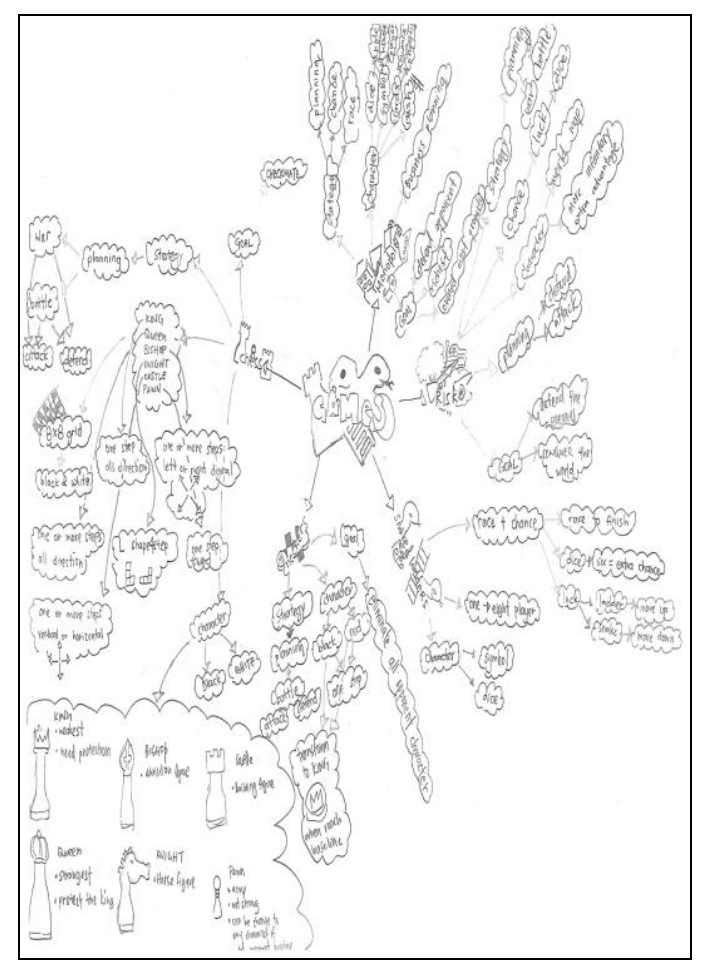

Fig. 5. Example of paper-based concept map [12].

Fig. 5 shows the paper-based concept map done by students who have to take the Fundamental Games Design course [12]. This is the basic paper-based in generating the idea for games genre. At this stage the ideation of combining the games genre that exist in the games world has been tremendous challenge towards game designers. 


\section{CONCEPtual Model For KnOWledge Sharing ToOl}

This study contributes to the field of concept maps as cognitive tools, or what Jonassen [13] calls "mindtools. In parallel with the recent advancements in computer-based visualization, there has been growing interest in the application of concept map to enhance the quality of teaching and learning in higher education [14].

Since knowledge entering the institutional organization can sometimes be tacit whereby it is difficult to transfer to another person by means of writing it or verbalizing it. Furthermore, it is very important for organization to visualize the knowledge and help others to understand the information better.

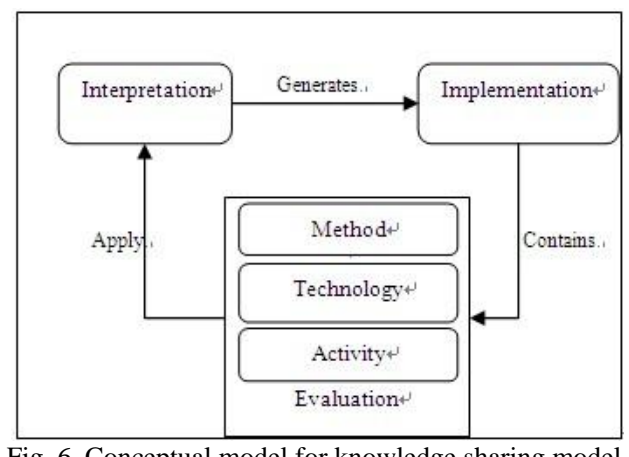

Fig. 6. Conceptual model for knowledge sharing model.

Fig. 6 shows the conceptual model for knowledge sharing model in this study where it rely on the concept map as knowledge visualization tool. The model also will be used as facilitative tool for individual in the organization to develop their capturing, analyzing and organizing knowledge as partial their daily routine in knowledge sharing lifecycle.

\section{DiSCUSSION AND FUTURE DIRECTIONS}

Organizational knowledge creation is the process of making available and amplifying knowledge created by individuals as well as crystallizing and connecting it to an organization's knowledge system [15].

The model described in this paper is the means to support the understanding of subject matter knowledge and concepts map. The understanding include problem-solving and design skills. This conceptual model will be spearheading for the development of a knowledge visualization prototype for game designers to engage them in an active learning constructivist manner for acquiring the concepts of designing games.

However, in this study, the fundamental of knowledge is rooted then individuals can readily apply it to multiple learning and disciplinary contexts. This work will also support the important goal of providing a solid foundation for lifelong learning for each individual.

\section{CONCLUSION}

This early stage of the study has been rooted in exploring the tacit knowledge in the individual knowledge. Thus the tacit knowledge in the organizational has the potential impact on the approach of the knowledge visualization techniques in multidisciplinary context.

\section{ACKNOWLEDGMENT}

H. Hussain thanks the group of game designers who willing to draw the paper-based concept-map for the pilot project. Moreover, these young game designers are enjoying the workshop to establish and enhance their knowledge in game development.

\section{REFERENCES}

[1] J. D. Novak, Learning, Creating, and Using Knowledge: Concept Maps As Facilitative Tools in Schools And Corporations, $2^{\text {nd }}$ ed., New York, NY: Routledge, 2010, ch. 6, pp. 90-130.

[2] J. D. Novak and D. B. Govin, Learning How to Learn, New York: Cambridge University Press, 1984, ch. 2, pp. 15-40.

[3] J. D. Novak and A. J. Canas, "Applying Educational Tools and Ideas in the Corporate World," in Applied Concept Mapping : Capturing, Analyzing, and Organizing Knowledge, B. M. Moon, R. R. Hofman, J. D. Novak, and A. J. Canas ed., CRC Press: Taylor \& Francis Group, FL: Boca Raton, 2011, ch. 1, pp. 3-21.

[4] M. H. Kang, Y. G. Kum, and G. W. Bock "Identifying Different Antecedents for Closed VS Open Knowledge Transfer," Journal of Information Science, vol. 36, no. 5, pp. 585-602, Oct. 2010.

[5] D. D. Long and L. Fathey, "Diagnosing Cultural Barriers to Knowledge Management," Academy of Management Executives, vol 14, no. 4, pp. 113-127, 2000.

[6] S. J. Jo, and B. K. Joo, "Knowledge sharing: the influence of learning organizational culture, organizational commitment, and organizational citizenship behaviors," Journal of Leadership and Organizational Studiess, vol. 18, no. 3, pp. 353-364, May 2011.

[7] V. Newman, "Redefining knowledge management to deliver competitive advantage," Journal of Knowledge Management, vol. 1 no. 2, pp. 123-32, 1997.

[8] J. B. Alan, E. R. W. Charles, and B. David, "Knowledge management: strategy or software?" Management Decision, vol. 38, no. 9, pp. 601-606, 2000.

[9] I. Nonaka and H. Takeuchi, The Knowledge-Creating Company, New York, Oxford: Oxford University Press, 1995, ch. 3, pp. 56-94.

[10] I. Nonaka and R. Toyama, "The knowledge-creating theory revisited: knowledge creation as a synthesizing process," Knowledge Management Research \& Practice, vol. 1, pp. 2-10, 2003.

[11] R. R. Hoffman, J. W. Coffey, J. D. Novak, and A. J. Cañas, "Application of concept maps to web design and web work," in Handbook of human factors in web design, R. W. Proctor and K.-P. L. Vu eds., Mawah, NJ: Lawrence Erlbaum Associates, 2005, pp. 156-175.

[12] H. Hussain, "An Approach of Concept Map in Creating Idea For Game Designer," in Proc 3rd International Conference on Education and New Learning Technologies, Barcelona, Spain, 2011, pp. 5561-5565.

[13] D. H. Jonassen, C. Carr, and H. P. Yueh, "Computers as mindtools for engaging learners in critical thinking," TechTrends, vol. 43, no. 2, pp 24-32, March 1998.

[14] I. Kinchin, "A knowledge structures perspective on the scholarship of teaching \& learning," International Journal for the Scholarship of Teaching and Learning, vol. 3, no. 2, July 2009.

[15] I. Nonaka, "Tacit knowledge and knowledge conversion: controversy and advancement in organizational knowledge creation theory," Organization Science, vol. 20, no. 3, pp. 635-652, 2009.

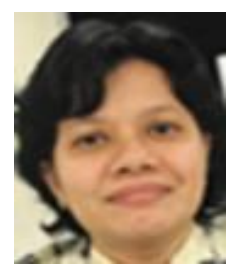

H. Hussain is a $\mathrm{PhD}$ candidate and a lecturer at Multimedia University, Malaysia. She is an academician with more than 15 years of work experience in education industry. She has obtained Master of Science in Computer Science and also Master of Science in Creative Multimedia.

Her current research interests are in the areas of knowledge management and information blended environment. visualizations. Thus, she also has an interest in

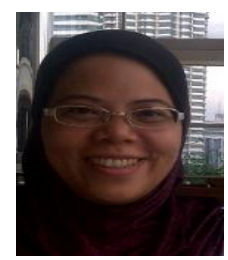

N. Shamsuar is a $\mathrm{PhD}$ candidate and a lecturer at Multimedia University, Malaysia. She holds Master of Science in Creative Multimedia. Her research areas are creative content and technologies focusing on multimedia reusability. 